\title{
College English Listening Teaching based on Schema Theory
}

\author{
Zhengrong Ma
}

Teaching and Research Institute of Foreign Languages, Bohai University, Jinzhou, 121013, China

bluestocking@163.com

Keywords: schema theory; college English; listening teaching; application; enlightenment

\begin{abstract}
Schema theory is a theory that cognitive psychologists explain human cognitive psychology process. Listening comprehension is the result of the interaction between the existed knowledge and input information in the listeners' mind, which is the interaction mode of "bottom-up" and "top-down". In the process of college English listening teaching, building languages and schemas' contents, activating existing schemas to improve the students' initiative and teaching effect. On the basis of the schema theory, this paper studies the schema theory application, classifies the schema in listening teaching, puts forward the enlightenment that the schema theory to college English teaching, specifically including: cultivating understanding ability and prediction ability, enriching the schema of each teaching link and cultivating culture background knowledge and so on. The research results of this paper enrich the listening teaching method, which can help students to improve their English listening comprehension ability.
\end{abstract}

\section{Introduction}

College English teaching is an organic composition part of higher education, college English course is a compulsory basic course of college students. College English is the teaching system which takes the foreign language teaching theory as the guide, English language knowledge and application skills, intercultural communication and learning strategies as the main content, and integrates a variety of teaching modes and teaching means. The teaching aim of college English is to cultivate students' English comprehensive application ability, especially listening and speaking skills, which makes them in the future study, work and social activities can communicate effectively in English, meanwhile, enhances their self-learning ability and improves the comprehensive cultural quality to adapt to our country's social development and the need of international communication.

English listening is the most important content of five skills (listening, speaking, reading, writing and translating) of students' English language, according to statistics, in the information people obtain, seventy-five percentage come from the process of listening and speaking, and listening occupies forty-five percentage, speaking occupies thirty percentage, the rest of the information come from the process of reading and writing. But in the practical English listening teaching, many teachers are accustomed to putting the tape, doing exercises and answering, or as the means to make the transition to other classroom activities, the real meaning of the listening teaching is weak, the authenticity of listening activities and the subjectivity of students' learning have not been reflected, teachers usually interpret from aspects such as words, phrases and syntax in the listening material, ignore the background knowledge which is closely related to the listening material. The study found that the process of listening comprehension is not just a passive receiving process, but also contains the initiative of the listener. All aspects of the background knowledge the listener has to a large extent influence the effectiveness of listening comprehension. The theory of the influence of this kind of background knowledge on listening comprehension is the schema theory. This paper studies the application of schema theory in English listening teaching from the aspects such as schema theory, the information processing way in the listening process, how schema theory guides the listening teaching and so on. 


\section{Schema Theory Foundation}

There are a lot of external structural understandings on an external object in everybody's brain, Schema is the cognitive structure or knowledge structure which exists in memory. Schema is an abstract of a large number of individual cases for things in life, and summarizes the important features of these things, not only refers to the conceptual understanding of things, but also includes the procedural understanding of things. Schema is stored in the brain, which is from past experience, and a general understanding of the repeated recurring situation, omitted details and summarized the common characteristics of some similar situations. Modern schema theory emerges after absorbing the point of view that rationalism's psychological structure thoughts and empiricism's past experiences which have a positive influence on psychology, and on the basis of the new achievements that the characterization studies of information science, computer science and psychology achieve. Think schema is learned and acquired through direct or indirect experience on the environment over period of time, which has the acquired character. The cognitive process of schema theory is illustrated in Fig. 1.

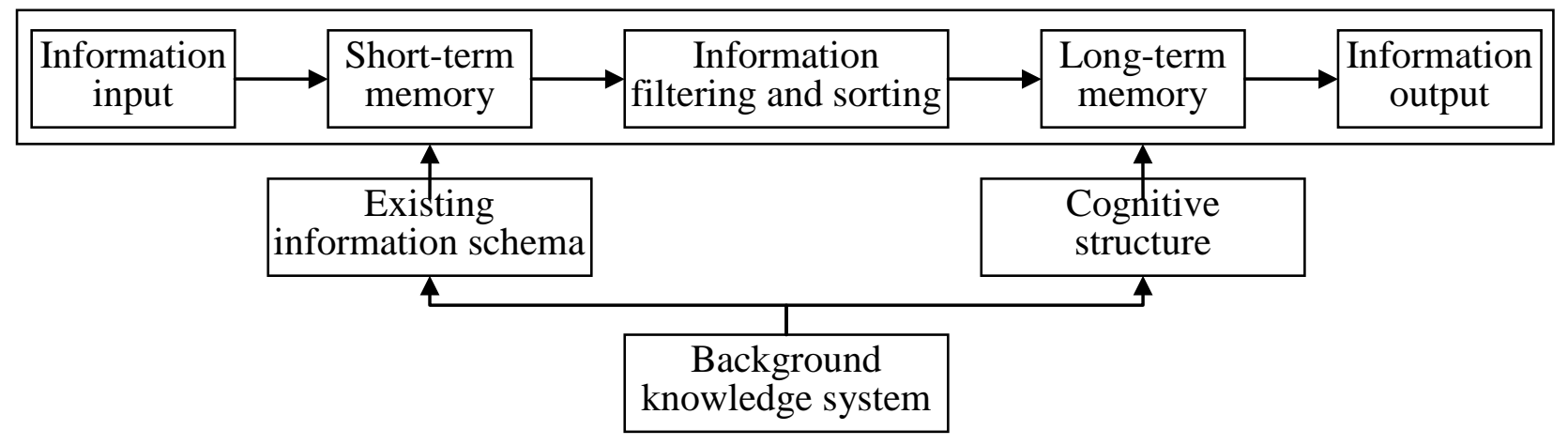

Fig. 1. Cognitive process of schema theory

\section{Schema Theory Application}

Schema theory is helpful for students to form a good cognitive structure. American cognitive psychologist D.P.AuSubel stresses that meaningful learning is to connect new knowledge with original knowledge, incorporate new knowledge into the original knowledge structure. It seems that the student's cognitive structure is the growing point of new knowledge, helping students to establish good cognitive structures is the basis of learning. Schema has a positive effect on cognitive structures, which can help students to build up good a cognitive structure. First of all, teaching students to construct the schema, optimizing the cognitive structure. A good cognitive structure has two characteristics, one is that stored knowledge are all "production", the second is that the nodes between knowledge have a high degree of organization, which are easy to activate, ease to migrate. The cognitive structure is a kind of schema, the premise of correct selection and flexible use of the schema is to constantly construct schema.

In the process of constructing the schema, it is to achieve condition and organization, teach students to combine the constructed schema with "trigger" conditions to form the conditional schema. Also teach students to link a scheme with others to form the organizational schema. The process of constructing the scheme is the process of forming the cognitive structure;

Teach students to form schema migration ability, enrich the cognitive structure. The cognitive structure is static, but as itself it is also dynamic and open, which needs to constantly absorb new knowledge, improve the abstract level of knowledge, this is realized in the application of knowledge and the schema's migration. After the knowledge structure of the system is transformed into the schema, we can learn by analogy, assimilate new information. In the process of the schema's migration, students' cognitive structure will be constantly enriched and developed;

Teach students to combine the schema with other learning strategies, improve the cognitive 
structure. A good cognitive structure has not only high level of knowledge representation abstraction, but also complete knowledge types, the descriptive knowledge, the procedural knowledge and the strategic knowledge, at present the students' cognitive structures just lack the strategic knowledge, so it is not perfect. As a learning strategy, the schema is a high-level learning strategies. It is essential that combined with other learning strategies in the applying process, which can better play the role of schema.

\section{Classification of Schemata in Listening Teaching}

The Schema theory thinks, in the process of listening, people use two ways of "bottom-up" and "top-down" to deal with information. The "bottom-up" information processing refers to the process that the listener calls a higher level schema from the lowest level schema, which is the process of decoding, that is beginning with identifying the minimum unit of the language's letters and words, gradually understanding the larger language's units of phrases, clauses and sentences, until the meaning of the whole text is mastered. The "top-down" information processing mode is just on the contrary, the listener according to the inspired high-level schema looks for the child schema, foreign scholars describe this process as "a psychological guessing game". According to this mode, the listener selects enough information from listening materials to make predictions, using background knowledge which refer to that all kinds of knowledge stored in the memory, including experiences, experience, objective world knowledge and the language knowledge to verify the predictions. The background knowledge related to the material is activated and consistent with the language input to achieve the purpose of understanding. The schema in the listening teaching is divided into the following three categories:

First, language schema. The language schema is the basis of the schema theory, which refers to the language knowledge learners master, including pronunciation, vocabulary and grammar and so on. Continuous reading, quietly reading, burst and assimilation make speech skills to be used with ease, otherwise they will become the obstacles of listening comprehension. This requires teachers to play a corresponding instructing role in the listening course, not only require students to practice the intensive listening, but also apply the schema theory, who arrange the corresponding macro-listening training combined with the characteristics of English listening.

Second, content schema. The content schema has certain structural features, on the basis of aesthetic judgment, which lines up the perceived external world in a particular way, and associates the integrated perceived world with the experience context in a certain relationship. In the listening comprehension, the content schema refers to the degree that the listener's familiarity with the listening material subject and its cultural background. When people understand the input information, it is necessary to associate the input information with the known information interaction in the brain which can achieve real understanding.

Third, formal schema. The formal schema refers to the knowledge listeners have in the aspects of chapters and question types. If the listener's mind has the form schema in advance and in the process of listening comprehension can timely activate the correct form schema, which can make correct predictions on the listening text structure and logical relations, contribute to the understanding of the listening chapter, in an active status in the process of listening comprehension, so as to accurately grasp the listening content, improve the level of listening comprehension.

\section{Enlightenment of Schema Theory to College English Listening Teaching}

Based on the schema theory, English listening classroom teaching mode is divided into three stages: pre-listening review stage, listening comprehension stage and after-listening digestion stage. The first stage is mainly that teachers prepare relevant background knowledge, introduce students into the learning state, and combine with multimedia to activate the relevant schema existed in the students' minds; the second stage is mainly that guide students to carry on the reasoning and analysis of the whole listening material through the top-down way to grasp the mean idea of the thesis, at the same time combine with the bottom-up approach to make understanding of detail parts; 
the third stage is mainly that teachers lead students to review material contents, and carry on the depth of mining on the material information to help students to complete the establishment of a new schema. With reference to relevant research results, the enlightenment of schema theory to college English listening teaching is as follows:

First, cultivate the ability of understanding. Combining the "bottom-up" mode and "top-down" mode can correctly understand the listening materials. Encountering understanding obstacles in the process of listening, one of the reasons is that errors occur when transferring the information from the schema system, or the schema system does not exist the contents adapt the information conveyed by listening materials. Therefore, it not only pays attention to language factors and ignores the relevant background knowledge in the process of listening, understanding an article is the process that listener's background knowledge interact with the listened material. When the schema knowledge matches the students' accepted language information, the related accumulation is increased in the mind. Before listening, constructing a schema mode in the student's mind becomes extremely important. Due to the introduction of the schema theory, the intellectual and non- intellectual obstacles are overcome in the process of students' listening, and the teaching effect is obviously improved.

Second, train the ability of predicting. The ability of predicting is the basic skills of language communication, a kind of important listening skills, which can effectively improve the level of listening comprehension. Listening comprehension process is a process of prediction, reasoning and verification. In this process, students use the knowledge to search for information, predict the content of the material and finally confirm. In this sense, the process of listening comprehension is also the process that teachers guide students to learn to use the known knowledge to know and understand the unknown. Teachers should help students to activate the schema, at the same time, establish a new schema, predict the input information, and prepare for the listening comprehension preparation stage. The more active schema, the more active listening comprehension process. Training the ability of the listening prediction mainly has the following three methods: one is that through the given option of the content after quickly browsing the listening material, conferring the listening content and possible asked questions; second is that pay attention to grasp the key words appear in different occasions, according to a certain vocabulary judge the place of occurrence and the relationship between speakers and so on; three is that according to the topic sentence predict the content of the entire article, according to the logical order of things' developments eventually accurately understand the full text.

Third, rich the schema of each teaching link. In the process of teaching design, teachers should design a lot of links which can help students build the schema continuously, and make good prepare for better developing listening teaching. The teaching content should be active to activate the schema stored in the student's mind, at the same time, effectively uses the existing schema to help students build a new schema, purposefully guides students to accumulate culture, history and geography knowledge, lets students understand that in the process of listening comprehension all kinds of cultural background knowledge is the key element which accurately grasp of the material's content. Teachers can help students to accumulate all kinds of background knowledge, combine with relevant contents to predict the listening content through the relevant materials provided in the teaching materials, including words, historical background and exercises.

Fourth, cultivate cultural background knowledge. Language and culture are closely intertwined, language is not only the product or result of the whole culture, but also the medium that forms and communicates other components of the culture. In the process of English listening, it often appears that understand the material's content, but not understand the meaning, this is caused due to the lack of cultural background knowledge. Background knowledge plays an important role in the listening comprehension, the inherent schema in the mind is the key factor to determine the listening comprehension. Students grow in the mother tongue culture atmosphere, judgment standard and values have the differences between the target language, thus the schema formed in the mind is not perfect, when making listening comprehension will mistakenly understand the true meaning materials convey. Therefore, teachers should pay attention to the culture teaching, let students make 
more understanding of the historical tradition, biographies, life style and local conditions and customs of English countries, and help students form a complete cultural schema. At the same time, guide students to place themselves in a relatively complete language background, which consciously compares the Chinese and Western culture to improve the cultural sensitivity, and cultivate the habit of English thinking, as far as possible to get rid of the inherent cultural patterns in the mind, and overcome the influence of the mother tongue, quickly and effectively understand English listening materials.

\section{Conclusion}

The Schema theory enriches the listening teaching methods, training students to effectively combine the known information such as linguistic schema, formal schema and content schema, more accurately understand material contents, which reaches the purpose of improving students' listening level. The Schema theory suggests that the ability that a person interprets the text is closely related with the schema stored in the brain, therefore, in the process of college English listening teaching, teachers should start from three aspects of the schema theory to activate students' background knowledge, stimulate students' interest in listening courses, and reshape students' confidence in listening, improve listening ability. When enrich students' background knowledge, also should actively cultivate students' prediction ability to the listening content, because the prediction ability based on the schema can effectively eliminate various understanding obstacles in the text, enhance students' ability to understand the deep meaning of the text. The Schema is not immutable, but a dynamic organization that constantly expands and reforms information, therefore after listening materials, teachers should also teach students how to summarize the information provided by internalized materials, only in this way, the schemas stored in students' mind are likely to expand continuously, which lays a solid foundation for further improving the listening ability.

\section{References}

[1] X. P. Wu, "Research on College English Listening Teaching from the perspective of Schema Theory," Time Education, vol. 13, no. 1, pp. 66-67, 2016.

[2] L. H. Jian, "English listening teaching model based on Schema Theory," Journal of Hunan University of Science and Engineering, vol. 36, no. 9, pp. 127-128, 2015.

[3] Y. F. Liu, "Research on Listening Teaching Strategies in Schema Theory," Journal of Qiqihar Junior Teachers' College, vol. 34, no. 3, pp. 143-144, 2014.

[4] J. Nong, "The Application of Schema Theory in the Teaching of Guangxi Independent College English Listening," Theory Research, vol. 53, no. 31, pp. 194-196, 2011.

[5]

360 personal library,

"Schema

theory," http://www.360doc.com/content/13/0929/11/2775069_317810180.shtml, 2016-9-21.

[6] M. Ma, Z. Zhang, "The Application of Schema Theory in College English Listening Teaching," Overseas English, vol. 12, no. 8, pp. 146-147, 2011.

[7] Z. X. Zhang, "College English Listening Teaching from the perspective of Schema Theory," Journal of Changchun University of Science and Technology(Social Sciences Edition), vol. 24, no. 5, pp. 164-166, 2011.

[8] X. H. Feng, "Schema theory and listening teaching of English Majors in Normal Colleges," Northern Literature, vol. 2, no. 11, pp. 126-127, 2011.

[9] Y. Bai, "The application of Schema Theory in English Listening Teaching," Science \& Technology Information, vol. 28, no. 8, pp. 591-592, 2011. 
[10] Y. Y. Zhang, "IELTS listening teaching from the perspective of Schema Theory," Chinese off campus education, vol. 8, no. 15, pp. 81-82, 2014.

[11] C. Y. Long, "Course group construction," Modern Education Science, vol. 4, no. 2, pp. 139-141, 2010. 